FELÍCIO NOGUEIRA COSTA

\title{
Pena privativa de liberdade decorrente de colaboração premiada: aplicação e execução
}

\author{
Dissertação de Mestrado \\ Orientador: Professor Titular Dr. Antonio Magalhães Gomes Filho
}

UNIVERSIDADE DE SÃO PAULO

FACULDADE DE DIREITO

São Paulo - SP 

FELÍCIO NOGUEIRA COSTA

\title{
Pena privativa de liberdade decorrente de colaboração premiada: aplicação e execução
}

\author{
Dissertação apresentada à Banca \\ Examinadora do Programa de Pós- \\ Graduação em Direito, da Faculdade de \\ Direito da Universidade de São Paulo, como \\ exigência parcial para a obtenção do título de \\ Mestre em Direito, na área de concentração \\ Direito Processual, sob a orientação do \\ Professor Titular Dr. Antonio Magalhães \\ Gomes Filho
}

UNIVERSIDADE DE SÃO PAULO

FACULDADE DE DIREITO

São Paulo - SP 
Autorizo a reprodução e divulgação total ou parcial deste trabalho, por qualquer meio convencional ou eletrônico, para fins de estudo e pesquisa, desde que citada a fonte.

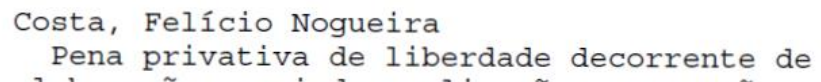


Nome: COSTA, Felício Nogueira

Título: Pena privativa de liberdade decorrente de colaboração premiada: aplicação e execução

Dissertação apresentada à Banca Examinadora do Programa de PósGraduação em Direito da Faculdade de Direito da Universidade de São Paulo, como exigência parcial para a obtenção do título de Mestre em Direito, na área de concentração Direito Processual, sob a orientação do Professor Titular Dr. Antonio Magalhães Gomes Filho

Aprovado em:

\author{
Banca Examinadora
}

Prof.

Instituição:

Julgamento:

Prof.

Instituição:

Julgamento:

Prof.

Instituição:

Julgamento: 



\section{AGRADECIMENTOS}

Ao Professor Antonio Magalhães Gomes Filho pela orientação no correr de minha jornada de estudos.

À Juliana Menezes pela companhia, amor e dedicação com a qual sempre me cerca.

À Ana Clara Rasuck pelo constante aprendizado que me proporcionou.

Aos meus pais, Sueli e Roberto, e à minha irmã Fabíola por terem me acompanhado até aqui.

A Flávia, Guilherme, Camila, Theuan, Pedro e Gabriela pelo conselho e companhia diários.

A Aurélio, Raquel, Luana e demais bibliotecários e funcionários da Faculdade de Direito da Universidade de São Paulo, bem como da Biblioteca Alceu Amoroso Lima e da Biblioteca Mário de Andrade. 



\section{RESUMO}

COSTA, Felício Nogueira. Pena privativa de liberdade decorrente de colaboração premiada: aplicação e execução. 2020. 154 p. Mestrado - Faculdade de Direito, Universidade de São Paulo, 2020.

A presente dissertação aborda a interação entre a colaboração premiada e a execução da pena do colaborador, com enfoque na pena privativa de liberdade. A abordagem se desenvolve pela análise histórica do instituto, culminando na promulgação da Lei 12.850/2013, marco no ordenamento brasileiro por delinear um regime negocial centrado na figura do acordo de colaboração premiada. São analisadas as denominadas três feições dos acordos de colaboração premiada: acordo para não oferecimento de denúncia, colaboração premiada atuante na sentença condenatória e a colaboração premiada posterior ao trânsito em julgado da sentença. Todos os benefícios da colaboração premiada previsto em lei são analisados de maneira individualizada no correr do trabalho, bem como os diversos institutos da execução penal, com apontamentos a acordos de colaboração premiada publicizados no âmbito da Operação Lava Jato. Tal conjunto de investigações é alvo de especial consideração por parte do autor, que analisa em profundidade o modelo de acordos de colaboração cristalizado na Orientação Conjunta $n^{\circ}$ 1/2018 do Ministério Público Federal. Tal modelo prega uma ampla expansão do âmbito de negociação entre as partes celebrantes do acordo de colaboração, fenômeno que seria contrário aos fundamentos do ordenamento brasileiro. Questiona-se a existência de um novo modelo de justiça penal no Brasil decorrente do emprego da colaboração premiada, de tal forma a delinear o que efetivamente há de inovador na Lei 12.850/2013, interpelação que se dá através da análise crítica sobre a expansão dos mecanismos de justiça criminal negocial no contexto nacional.

Palavras-chave: Processo Penal, Execução da Pena, Colaboração Premiada 



\begin{abstract}
COSTA, Felício Nogueira. Prison sentence arising from a state's evidence deal: admissibility and enforcement. 2020. 154 p. Master - Faculty of Law, University of São Paulo, São Paulo, 2020.

This dissertation discusses the interaction between state's evidence deals in Brazil and the execution of the whistleblower's sentence, with focus on the imprisonment sentence. The approach is developed by a historical analysis of the state's evidence deal regulation leading to the enactment of the Law 12.850/2013, a milestone in the Brazilian legal system which outlined a bargaining regime focused on a written agreement. The so-called three features of the state's evidence deal are analyzed: a deal to not file criminal charges, state's evidence deal that affects the conviction and state's evidence deal after the court's decision becomes final and non-appealable. The dissertation analyzes all the state's evidence deal clauses provided for by law to soften the whistleblower's sentence, especially the ones included in agreements that are part of the Car Wash Operation (Operação Lava Jato). Such set of investigations is subject to special consideration by the author, who analyzes in depth the agreement model set forth in the Joint Guidance $n^{\circ} 1 / 2018$ of the Federal Prosecution Office. Such model provides for a broader-based bargain agreement contrary to the foundations of the Brazilian legal system. The author analyzes the existence of a new criminal justice model in Brazil arising from those agreements, in such a way as to outline what is indeed innovative in the Law 12.850/2013. This work offers a critical analysis of the expansion of the criminal justice bargain mechanism in the Brazilian legal framework.
\end{abstract}

Keywords: Criminal Procedure, Prison Sentence, State's Evidence Deal 



\section{LISTA DE ILUSTRAÇÕES}

Figura única: Momento de incidência de benefícios. 



\section{SUMÁRIO}

1. INTRODUÇÃO 15

2. COLABORAÇÃ̃ PREMIAdA NO BRASIL .................................................... 19

2.1. Histórico legislativo prévio à Lei 12.850/2013 ............................................ 19

2.1.1. Lei 8.072/1990 - crimes hediondos ............................................... 19

2.1.2. Lei $9.034 / 1995$ - crime organizado ................................................ 22

2.1.3. Lei 9.080/1995 e 9.613/1998 - crimes financeiros ............................. 27

2.1.4. Lei 9.807/1999 - proteção a colaboradores .......................................... 30

2.1.5. Leis 10.409/2002 e 11.343/2006 - leis de drogas .............................. 32

2.1.6. Outros mecanismos premiais - acordo de leniência ........................... 34

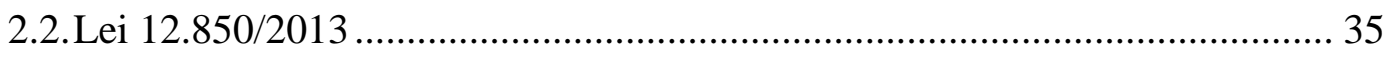

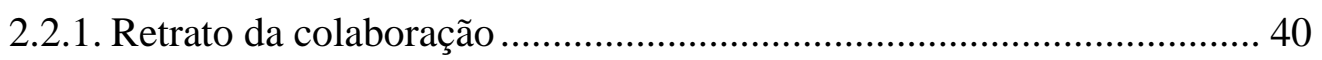

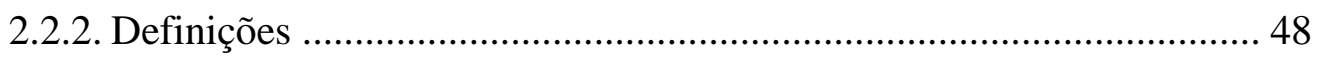

2.2.3. A Lei 12.850/2013 e sua interação com outros regimes premiais ....... 52

3. EXECUÇÃO PENAL E JUSTIÇA NEGOCIADA...................................... 57

3.1. Colaboração premiada e sua tripla feição .................................................... 57

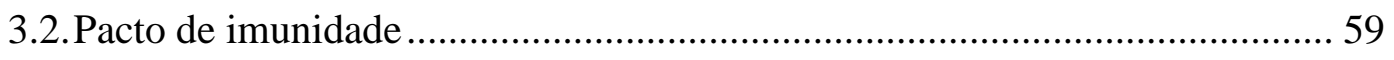

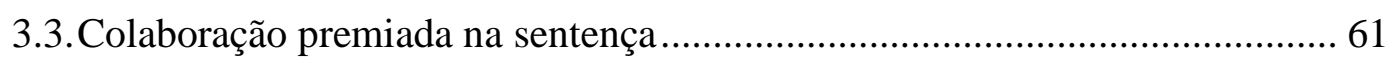

3.3.1. Benefícios aplicáveis na decisão condenatória ................................. 61

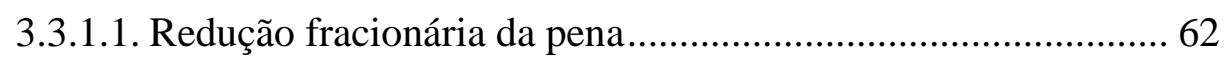

3.3.1.2. Cumprimento de pena em regime diverso .............................. 66

3.3.1.3. Substituição por pena restritiva de direito ............................... 70

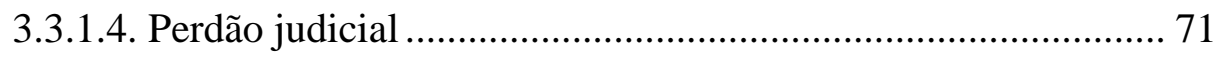

3.3.2. Destaque: a busca por um modelo de atribuição de benefícios em acordos de colaboração premiada ........................................................ 72

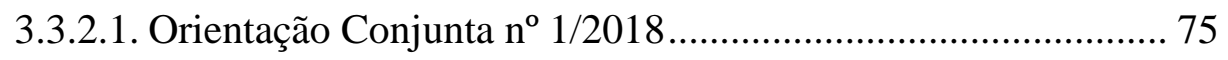

3.3.2.2. A reação ao modelo de acordos da Operação Lava Jato cristalizado na Orientação Ministerial .................................... 87

3.4. Colaboração premiada na execução ........................................................... 92

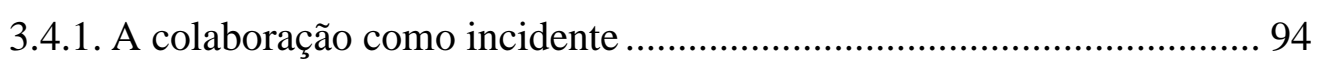

3.4.2. Execução antecipada da pena privativa de liberdade......................... 99

3.4.3. Execução da pena do colaborador..................................................... 105

3.4.3.1. Sistema progressivo .......................................................... 106

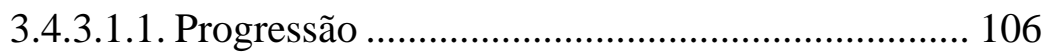


3.4.3.1.2. Regressão 110

3.4.3.1.3. Livramento condicional ..................................... 111

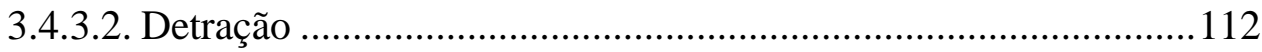

3.4.3.3. Remição ............................................................................... 113

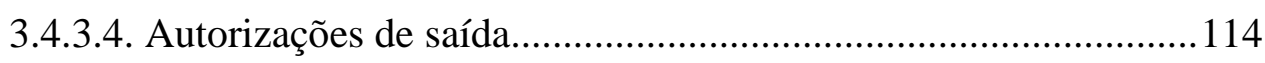

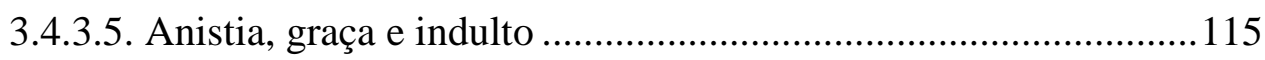

3.5. Lei 12.850/2013: criação de um novo modelo de justiça penal? .............118

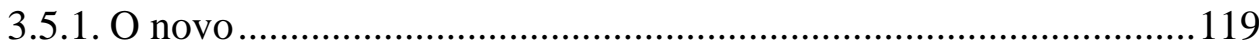

3.5.2. Conhecidos institutos sob nova roupagem ..................................122

3.6. Pergunta instigante: seria possível um acordo de colaboração tão somente para cumprimento da Lei?................................................................. 127

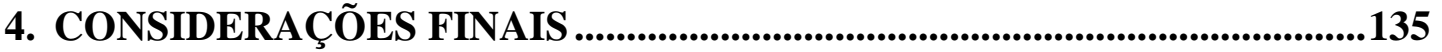




\section{INTRODUÇÃO}

A colaboração premiada, comumente chamada também de delação premiada ${ }^{1}$, ganhou em tempos recentes os holofotes da imprensa nacional e a atenção dos juristas. Hoje designada como meio de obtenção de prova e negócio jurídico processual ${ }^{2}$, a colaboração premiada reivindicou o papel de instrumento da persecução penal de delitos cometidos no âmbito da criminalidade organizada, contando com novo diploma normativo.

A partir da Lei 12.850/2013, a colaboração passou a ter um tratamento tendente à sistematização, especialmente em relação ao procedimento para realização do acordo. Ela é assim cabível no contexto de organizações criminosas para a identificação de coautores e das infrações penais por eles praticadas, revelação da estrutura hierárquica e da divisão de tarefas, prevenção de infrações penais futuras, recuperação do produto ou proveito de infrações penais e localização de eventual vítima com sua integridade física preservada.

Dito isso, o instituto está intrinsecamente relacionado à pactuação de benefícios penais, com inevitáveis reflexos na execução da pena que venha a recair sobre o colaborador - quando houver efetiva pena a ser executada, visto ser possível a pactuação que exima o colaborador de qualquer processo.

O presente trabalho busca assim analisar a pena privativa de liberdade resultante da colaboração premiada, desde os limites de disponibilidade sobre a pena quando alvo de acordo, até a execução em si da reprimenda; conquanto os prêmios derivados da colaboração premiada não se limitem a essa espécie de pena, também chamada de pena corporal. Em suma, cumpre analisar quais cartas estão na mesa quando se negocia a liberdade em um acordo de colaboração e quais as consequências desse negócio jurídico sobre a pena privativa a ser cumprida.

Nesse contexto, é inegável a importância adquirida pelos acordos de colaboração firmados na chamada Operação Lava Jato, conjunto de diversas investigações iniciadas no ano de 2014 para apuração de crimes de corrupção, lavagem de dinheiro, organização criminosa, fraude à licitação e outros, inicialmente no âmbito da estatal Petrobras.

\footnotetext{
${ }^{1}$ Trataremos ambos os termos como sinônimos. A distinção de nomenclatura empregada por alguns é tema explorado no item 2.2.2.

${ }^{2}$ Com suas nuances, como veremos mais adiante. A colaboração premiada foi recentemente aprimorada através da Lei 13.964/2019 (ainda não vigente ao tempo da conclusão do presente trabalho), que dita: "O acordo de colaboração premiada é negócio jurídico processual e meio de obtenção de prova, que pressupõe utilidade e interesse públicos".
} 
Conquanto diversos outros acordos de colaboração tenham sido firmados antes mesmo da operação em questão, ou até mesmo antes da Lei das Organizações Criminosas atualmente vigente (Lei 12.850/2013), o porte das investigações e sua visibilidade tornaram a Operação verdadeiro celeiro da colaboração premiada. Nela floresceu uma profusão de acordos, com grande leque de benefícios concedidos, vários deles expandindo em muito o espectro de negociação avistado na legislação premial.

Essa a razão pela qual, por diversas vezes e em razão da disponibilidade de acesso, faremos menção a acordos de colaboração provenientes da Operação Lava $\mathrm{Jato}^{3}$, a exemplo daqueles firmados por Alberto Youssef (Pet. 5.244 Supremo Tribunal Federal - STF) ${ }^{4}$, Antonio Palocci Filho (Pet. 5016846-28.2018.4.040000 Tribunal Regional Federal da $4^{\mathrm{a}}$ Região - TRF 4) ${ }^{5}$, Delcídio do Amaral Gomez (Pet. 5.952 STF) ${ }^{6}$, José Sérgio de Oliveira Machado (Pet. 6.138 STF) ${ }^{7}$, Nestor Cerveró (Pet. 5.886 STF) ${ }^{8}$, Paulo Roberto Costa (Pet. 5.210 STF) ${ }^{9}$ e Ricardo Pessoa Ribeiro (Pet. 5.624 STF) ${ }^{10}$. O Ministério Público Federal no Paraná, estado em que iniciadas as investigações em questão, relata ter firmado dezenas de acordos de colaboração premiada ${ }^{11}$; no âmbito do Supremo Tribunal Federal, responsável

\footnotetext{
3 A maioria dos acordos de colaboração mencionados no presente trabalho têm como parte celebrante o Ministério Público Federal. Quando não houver indicação contrária, o acordo citado se encaixa nessa regra.

4 Acordo de colaboração premiada assinado em 24 set. 2014 no âmbito das ações penais 502568703.2014.4.04.7000, 5025699-17.2014.4.04.7000, 5026212-82.2014.4.04.7000, 5047229-77.2014.4.04.7000, 5049898-06.2014.4.04.7000, 5035110-84.2014.4.04.7000 e 5035707-53.2014.4.04.7000, perante a 13 ${ }^{\mathrm{a}}$ Vara Federal da Subseção Judiciária de Curitiba/PR. Disponível em: <https://www.conjur.com.br/dl/acordodelacao-youssef.pdf >. Acesso em: 12 nov. 2019.

${ }^{5}$ Acordo de colaboração premiada assinado com a Polícia Federal em 21 mar. 2018 no âmbito do processo $n^{\circ}$ 5016846-28.2018.4.04.0000/RS, perante a $8^{\mathrm{a}}$ Turma do Tribunal Regional Federal da $4^{\mathrm{a}}$ Região.

${ }^{6}$ Acordo de colaboração premiada assinado em 4 mai. 2016 no bojo dos Inquéritos 4215/DF e 3989/DF perante o Supremo Tribunal Federal. Disponível em: 〈https://www.conjur.com.br/dl/peca-pet-6138.pdf >. Acesso em: 27 nov. 2019.

${ }^{7}$ Acordo de colaboração premiada assinado em 11 fev. 2016 no bojo dos Inquéritos 4215/DF e 3989/DF, todos perante o Supremo Tribunal Federal. Disponível em: <https://politica.estadao.com.br/blogs/faustomacedo/wp-content/uploads/sites/41/2016/03/308950183.pdf>. Acesso em: 12 nov. 2019.

8 Acordo de colaboração premiada assinado em 18 nov. 2015 no âmbito das ações penais 508383859.2014.4.04.7000/PR e 5007326-98.2015.4.04.7000/PR e no Inquérito Policial 5015255-85.2015.4.04.7000, perante a $13^{\mathrm{a}}$ Vara Federal da Subseção Judiciária de Curitiba/PR. Disponível em: <https://d2f17dr7ourrh3.cloudfront.net/wp-content/uploads/2016/06/Cerver\%C3\%B3-vol-1.pdf>. Acesso em: 27 nov. 2019.

9 Acordo de colaboração premiada assinado em 27 ago. 2014 no âmbito das ações penais 502567671.2014.4.04.7000 e 5026212-82.2014.4.04.7000, perante a 13 ${ }^{\mathrm{a}}$ Vara Federal da Subseção Judiciária de Curitiba/PR. Disponível em: <https://s.conjur.com.br/dl/acordo-delacao-premiada-paulo-roberto.pdf >. Acesso em: 13 nov. 2019.

10 Acordo de colaboração premiada assinado em 13 mai. 2015 no âmbito das ações penais 508325829.2014.4.04.7000 e 5083401-18.2014.4.04.7000, perante a $13^{\mathrm{a}}$ Vara Federal da Subseção Judiciária de Curitiba/PR. Disponível em: <https://politica.estadao.com.br/blogs/fausto-macedo/wpcontent/uploads/sites/41/2015/12/RPESSOA-1.pdf>. Acesso em: 27 nov. 2019.

11 Cf. informação disponível em: <http://www.mpf.mp.br/para-o-cidadao/caso-lava-jato/atuacao-na-1ainstancia/atuacao-na-1a-instancia/parana/resultado>. Acesso em: 8 de jul. 2018.
} 
pelo processamento dos feitos criminais relativos a detentores de foro por prerrogativa de função, foi submetida outra porção considerável de acordos de colaboração ${ }^{12}$.

Tamanha a repercussão do instituto, Polícia Federal e Ministério Público chegaram a regulamentar internamente o regime das colaborações premiadas a serem negociadas por seus membros. A praxe levou a reações diversas no mundo político e jurídico, dentre elas a reforma da Lei 12.850/2013 pela popularmente chamada Lei Anticrime ${ }^{13}$ (Lei 13.964/2013). Daí porque é inegável o vulto que a colaboração premiada adquiriu no contexto brasileiro, elevando a menor relevância que granjeava anteriormente, não obstante exista há aproximadamente duas décadas no ordenamento da República.

${ }^{12} C f$. informação disponível em: <http://www.mpf.mp.br/para-o-cidadao/caso-lava-jato/atuacao-no-stj-e-nostf/resultados-stf/a-lava-jato-em-numeros-stf >. Acesso em: 8 de jul. 2018.

13 Designação dada inicialmente a anteprojeto de Lei provindo do Ministério da Justiça, sob a gestão do Ministro Sérgio Fernando Moro; muito do seu conteúdo original, contudo, foi alterado no trâmite legislativo (vide Lei 13.964/2019). 


\section{CONSIDERAÇÕES FINAIS}

A Lei 12.850/2013 alçou a colaboração premiada à posição de destaque no contexto do direito processual penal. Sua ampla aplicação no âmbito da Operação Lava Jato cimentou o instituto no consciente popular e na prática jurídica como instrumento de persecução aos crimes cometidos por organizações criminosas, dada a existência de um procedimento que busca trazer segurança jurídica e de uma gama de benefícios penais que incentivam a colaboração.

A redução fracionária de pena deixou de ser o benefício central da delação premiada, confirmando a expansão avistada na Lei de Lavagem de Dinheiro (Lei 9.613/1998) e nas Lei 9.807/1999 e 10.409/2002. O colaborador premiado que integre organização criminosa pode vir a negociar diversos benefícios que impactarão sua pena: perdão judicial, redução de até dois terços da pena privativa de liberdade, substituição por pena restritiva de direito, progressão de regime ainda que ausentes os requisitos objetivos; ou mesmo prescindir de qualquer pena e mesmo do processo através do pacto para não oferecimento de denúncia.

No presente trabalho exploramos a tripla feição adquirida pelos acordos de colaboração, sob o viés da execução da pena e aplicação de benefícios, e nos centramos na análise dos impactos da colaboração premiada sobre a pena privativa de liberdade, recorte temático que nos permitiu aprofundar tanto na aplicação normal dos benefícios previstos em Lei, quanto na sua deturpação avistada na prática.

Uma abordagem seria incompleta sem a outra, na medida em que os acordos firmados no âmbito da Operação Lava Jato moldaram a colaboração premiada no contexto brasileiro, seja para o bem, seja para o mal. Uma série de delitos graves foi desvelada por inúmeras colaborações premiadas, no entanto a pactuação dos acordos fugiu da disciplina inscrita na Lei 12.850/2013 ou qualquer outra do ordenamento pátrio.

A análise do modelo de colaboração premiada avistado na Orientação Conjunta $n^{\circ}$ 1/2018 do Ministério Público Federal permitiu apontar diversos conflitos com o direito posto, dentre eles acordos de colaboração com fixação de penas corpóreas fixas, emprego da suspensão do processo como benefício per se, a proliferação dos regimes diferenciados. Execução antecipada da pena e outros conflitos com o modelo de execução penal pátrio também foram adereçados em títulos dedicados, cabendo aqui ainda o destaque à reforma processual penal promovida pela Lei 13.964/2019 contendo dispositivos específicos para coibir excessos na negociação de acordos de colaboração. 
Daí se conclui que a Lei 12.850/2013 trouxe inovações, mormente o pacto para não oferecimento de denúncia e as novas dimensões do perdão judicial do colaborador, ambos benefícios maiúsculos. Além deles, contudo, não houve inovações normativas de proporções ciclópicas, mas a expansão do direito premial pelo emprego de instrumentos jurídicos conhecidos, mesmo que atuando sob um renovado vetor, o acordo de colaboração premiada. A colaboração premiada seguirá como instrumento útil à apuração de delitos de difícil investigação, no entanto, ela não será remédio hábil para combater todos os males do sistema penal brasileiro. 


\section{REFERÊNCIAS BIBLIOGRÁFICAS ${ }^{335}$}

\section{Livros e artigos}

ARANHA, Adalberto José Q. T. de Camargo. Da prova no processo penal. 4a ed. São Paulo: Saraiva, 1996.

BALDAN, Édson Luís. O jogo matemático da delação e a extorsão da prova mediante sequestro do investigado. Boletim IBCCRIM, São Paulo, v. 13, n. 159, p. 4-6, fev. 2006. Disponível em: <http://201.23.85.222/biblioteca/index.asp?codigo_sophia=57183>. Acesso em: 2 jan. 2020.

BADARÓ, Gustavo Henrique; BOTTINI, Pierpaolo Cruz. Lavagem de dinheiro: aspectos penais e processuais penais: comentários à Lei 9.613 com as alterações da Lei 12.683/2012. 2a ed. São Paulo: Revista dos Tribunais, 2019.

Processo penal. Rio de Janeiro: Elsevier, 2012.

. Hipóteses que autorizam o emprego de meios excepcionais de obtenção de prova.

In: __ [et alii]; AMBOS, Kai; ROMERO, Eneas. Crime organizado: análise da lei 12.850/2013. São Paulo: Marcial Pons, CEDPAL, 2017.

. Limites do pactuado na Colaboração Premiada: pode o Ministério Público fixar penas ou conceder perdão? Badaró Advogados - artigos, 2018. Disponível em: <http://badaroadvogados.com.br/21-082018-limites-do-pactuado-na-colaboracaopremiada-pode-o-ministerio-publico-fixar-penas-ou-conceder-perdao.html>. Acesso em: 6 de jan. 2020.

. O Valor Probatório da Delação Premiada: sobre o $§ 16$ do art. $4^{\circ}$ da Lei n ${ }^{\circ} 12.850 / 13$. Badaró Advogados - artigos, 2018. Disponível em: <http://badaroadvogados.com.br/fevde-2015-o-valor-probatorio-da-delacao-premiada-sobre-o-16-do-art-4-da-lei-n-1285013.html>. Acesso em 27 nov. 2019.

${ }^{335}$ De acordo com a Associação Brasileira de Normas Técnicas (ABNT NBR 6023). 
. A necessidade de um regime legal próprio para o colaborador premiado. Consultor

Jurídico, 2019. Disponível em: <https://www.conjur.com.br/2019-set-24/gustavo-badarofigura-especifica-colaborador-premiado>. Acesso em: 4 de out. 2019

BARROS, Carmen Silvia de Moraes. A individualização da pena na execução penal. São Paulo: Revista dos Tribunais, 2001.

BARROS, Marco Antonio de. A lavagem de capitais e obrigações civis correlatas: com comentários artigo por artigo, à Lei 9.613/98. 4a ed. São Paulo: Revista dos Tribunais, 2013.

BECCARIA, Cesare. Dos delitos e das penas. Tradução Paulo M. Oliveira. Rio de Janeiro: Nova Fronteira, 2011.

BEMFICA, Francisco Vani. Da lei penal, da pena e sua aplicação, da execução da pena. Rio de Janeiro: Forense, 1996.

BENETI, Sidnei Agostinho. O processo de execução penal. Tese de doutorado sob orientação do Professor Rogério Lauria Tucci. São Paulo: Faculdade de Direito da Universidade de São Paulo, 1994.

BITENCOURT, Cezar Roberto; BUSATO, Paulo César. Comentários à lei de organização criminosa: Lei n. 12.850/2013. São Paulo: Saraiva, 2014

BITTAR, Walter Barbosa. Delação premiada: direito estrangeiro, doutrina, jurisprudência. Rio de Janeiro: Lumen Juris, 2011.

; BORRI, Luiz Antonio; SOARES, Rafael Junior. A questão da natureza jurídica e a possibilidade legal de impugnação do acordo de colaboração premiada pelo delatado. Boletim IBCCRIM, São Paulo, v. 27, n. 322, p. 19-21., set. 2019. Disponível em: $<$ http://201.23.85.222/biblioteca/index.asp?codigo_sophia=153025. Acesso em: 2 jan. 2020>. 
BOTTINI, Pierpaolo Cruz; MOURA, Maria Thereza de Assis (coord). Colaboração Premiada. São Paulo: Revista dos Tribunais, 2017.

Direito penal, processo penal e colaboração premiada na lei "anticrime". Consultor Jurídico, 6 jan. 2020. Disponível em:<https://www.conjur.com.br/2020-jan-06/direitodefesa-direito-penal-processo-penal-delacao-lei-anticrime>. Acesso em: 7 jan. 2020.

BOTTINO, Thiago. Colaboração premiada e incentivos à cooperação no processo penal: uma análise crítica dos acordos firmados na "Operação Lava Jato". Revista Brasileira de Ciências Criminais. São Paulo, v. 24, n. 122, ago. 2016.

BRANDALISE, Rodrigo da Silva. Justiça penal negociada: negociação da sentença criminal e princípios processuais relevantes. Curitiba: Juruá, 2016.

CABRERA, Raul Peña. Terminacion anticipada del proceso y colaboracion eficaz. $2 \mathrm{a}$ ed. Lima: Grijley, 1995.

CALLEGARI, André Luís. WEMUTH, Maiquel Ângelo Dezordi. Crime organizado: conceito e possibilidade de tipificação diante do contexto da expansão do direito penal. In: PRADO, Luiz Regis. DOTTI, René Ariel (coord.). Direito penal empresarial, crime organizado, extradição e terrorismo: volume VI. São Paulo: Revista dos Tribunais, 2011.

; LINHARES, Raul Marques. Colaboração premiada: lições práticas e teóricas: de acordo com a jurisprudência do Supremo Tribunal Federal. Porto Alegre: Livraria do Advogado, 2019.

CAMACHO, Fernanda Gomes. Mutabilidade da sentença penal condenatória: unificação e soma das penas. Dissertação de metrado sob orientação do Professor Sérgio Marcos de Moraes Pitombo, Faculdade de Direito da Universidade de São Paulo, 2002.

CANOTILHO, José Joaquim Gomes; BRANDÃO, Nuno. Colaboração premiada: reflexões críticas sobre os acordos fundantes da Operação Lava Jato. Revista Brasileira de Ciências Criminais. vol. 133. ano 25. São Paulo: Revista dos Tribunais, jul. 2017. 
CARVALHO, Érika Mendes de; ÁVILA, Gustavo Noronha de. Reflexões sobre a (i)legitimidade da delação premiada como comportamento pós-delitivo na execução penal. Revista Brasileira de Ciências Criminais, São Paulo, v. 27, n. 153, p. 109-132., mar. 2019. Disponível em: <http://201.23.85.222/biblioteca/index.asp?codigo_sophia=150400>. Acesso em: 5 jan. 2020.

CARVALHO, Natália Oliveira de. A delação premiada no Brasil. Rio de Janeiro: Lumen Juris, 2009.

CARVALHO, Salo de. Penas e garantias. Rio de Janeiro: Lumen Juris, 2003.

; LIMA, Camile Eltz de. Delação premiada e confissão: filtros constitucionais e adequação sistemática. In: GOMES, Marcus Alan de Melo (Coord.); PINHO, Ana Cláudia Bastos de (Coord.). Ciências criminais: articulações críticas em torno dos 20 anos da Constituição da República. Rio de Janeiro: Lumen Juris, 2008.

; LIMA, Camile Eltz de. Delação premiada e confissão: filtros constitucionais e adequação sistemática. In: GOMES, Marcus Alan de Melo; PINHO, Ana Cláudia Bastos de (coord.). Ciências criminais: articulações críticas em torno dos 20 anos da Constituição da República. Rio de Janeiro: Lumen Juris, 2008.

. Penas e medidas de segurança no direito penal brasileiro. 2a ed. São Paulo: Saraiva, 2015.

Colaboração premiada e aplicação da pena: garantias e incertezas dos acordos realizados na Operação Lava Jato. In: BEDÊ JUNIOR, Américo; CAMPOS, Gabriel Silveira de Queirós (coord.). Sentença criminal e aplicação da pena: ensaios sobre discricionariedade, individualização e proporcionalidade. Salvador: JusPODIVM, 2017. Disponível em: <http://201.23.85.222/biblioteca/index.asp?codigo_sophia=152231>. Acesso em: 18 out. 2019.

CASTILHO, Ela Wiecko V. de. Controle da legalidade na execução penal: reflexões em torno da jurisdicionalização. Porto Alegre: Fabris, 1988. 
CESCA, Brenno Gimenes. O espaço negocial das partes na colaboração premiada da lei de organizações criminosas e a averiguação de sua legalidade pelo juiz na fase homologatória. In: Boletim IBCCRIM, ed. 308, jul. 2018.

CHOUKR, Fauzi Hassan. Processo penal à luz da Constituição. Bauru: EDIPRO, 1999.

COELHO, Luís Carlos Honório de Valois. Conflito entre ressocialização e o princípio da legalidade penal. Dissertação de mestrado sob orientação do Professor Alvino Augusto de Sá. São Paulo: Faculdade de Direito da Universidade de São Paulo, 2012.

COUTINHO, Jacinto Nelson de Miranda. Delação premiada: posição contrária. Jornal Carta Forense, 2014. Disponível em: $<$ http://www.cartaforense.com.br/conteudo/artigos/delacao-premiada-posicaocontraria/13613>. Acesso em: 16 out. 2019.

COUTO, Marco. Delação premiada: o dito e o não dito. Curitiba: Juruá, 2018.

CORREAA JUNIOR, Alceu. Monitoramento eletrônico de penas e alternativas penais. Tese de doutoramento sob orientação do Professor Sérgio Salomão Shecaira, Faculdade de Direito da Universidade de São Paulo, 2012.

CORDEIRO, Nefi. Colaboração premiada: caracteres, limites e controles. Rio de Janeiro: Forense, 2020.

COSTA, Helena Regina Lobo da Costa. Ampliação dos acordos processuais penais, execução da pena antes do trânsito em julgado de sentença condenatória e o ocaso da dogmática penal como ciência prática. In: MALAN, Diogo; BADARÓ, Gustavo; ZILLI, Marcos; MOURA, Maria Thereza Rocha de Assis; SAAD, Marta; MORAES; Mauricio Zanoide de. [orgs.]. Processo penal humanista: escritos em homenagem a Antonio Magalhães Gomes Filho. Belo Horizonte, Editora D’Plácido, 2019. 
COSTA, Leonardo Dantas. Delação premiada: a atuação do estado e a relevância da voluntariedade do colaborador com a justiça. Curitiba: Juruá, 2017.

COSTA, Paula Bajer Fernandes Martins da. Igualdade no direito processual penal brasileiro. São Paulo: Revista dos Tribunais, 2001.

CRUZ, Flavio Antônio da. Plea Bargaining e Delação Premiada: Algumas Perplexidades. Revista Jurídica da Escola Superior de Advocacia da OAB-PR. Edição 02, dez. 2016. Disponível em: <https://www.academia.edu/32104639/PLEA_BARGAINING_E_DELA\%C3\%87\%C3\%8 3O_PREMIADA_ALGUMAS_PERPLEXIDADES?email_work_card=title>. Acesso em: 6 jan. 2020.

DELMANTO, Roberto. Leis penais especiais comentadas. 2a ed. São Paulo: Saraiva, 2014.

DE-LORENZI, Felipe da Costa. A determinação da pena na colaboração premiada: análise da fixação dos benefícios conforme a lei 12.850/2013 e o Supremo Tribunal Federal. Revista Brasileira de Ciências Criminais, São Paulo, v. 27, n. 155, p. 293-337., mai. 2019. Disponível em: <http://201.23.85.222/biblioteca/index.asp?codigo_sophia=151402>. Acesso em: 5 jan. 2020.

DIAS, Jorge de Figueiredo. A criminalidade organizada: do fenômeno ao conceito jurídicopenal. Revista Brasileira de Ciências Criminais, vol. 71/2008, mar./abr. 2008.

DIDIER JR., Fred; BONFIM, Daniela. Colaboração Premiada (Lei $n^{\circ}$ 12.850/2013): Natureza Jurídica e Controle da Validade por Demanda Autônoma - um Diálogo com o Direito Processual Civil. Revista do Ministério Público do Rio de Janeiro nº 62, out./dez. 2016. 23/59. D. Disponível em: <http://www.mprj.mp.br/documents/20184/1260352/Fredie_Didier_Jr_\%26_Daniela_Bom fim.pdf>. Acesso em: 6 jan. 2020.

DIPP, Gilson. A "Delação" ou Colaboração Premiada: uma análise do instituto pela interpretação da lei. Brasília: IDP, 2015. Disponível em: 
<https://www.academia.edu/31651151/A_Delacao_ou_Colaboracao_Premiada_IDP?email _work_card=title>. Acesso em 7 jan. 2020.

DOTTI, René Ariel. A atenuante da confissão. Argumenta Journal Law, Jacarezinho - PR, n. 6, p. 18-35, fev. 2013. Disponível em: <http://seer.uenp.edu.br/index.php/argumenta/article/view/55/55>. Acesso em: 17 out. 2019.

FATTORI, Thiago Alessandro. Breves considerações acerca da orientação conjunta 1/2018 do Ministério Público Federal: a negociação do acordo de colaboração premiada. Boletim IBCCRIM, São Paulo, v. 26, n. 312, p. 10-12., nov. 2018. Disponível em: $<$ http://201.23.85.222/biblioteca/index.asp?codigo_sophia=146839>. Acesso em: 2 jan. 2020.

FAYET, Paulo. Da criminalidade organizada. Porto Alegre: Núria Fabris, 2012.

FERNANDES, Antonio Scarance. Incidente processual: questão incidental, procedimento incidental. São Paulo: Revistas dos Tribunais, 1991.

. Crime organizado e a legislação brasileira. In: PENTEADO, Jaques de Camargo (coord.). Justiça penal: críticas e sugestões. São Paulo: Revista dos Tribunais, 1995.

. O equilíbrio na repressão ao crime organizado. In: ; ALMEIDA, José Raul Gavião de; MORAES, Maurício Zanoide de (coord.). Crime organizado: aspectos processuais. São Paulo: Revista dos Tribunais, 2009.

Processo penal constitucional, 7a ed., São Paulo, Revista dos Tribunais, 2012.

FERNANDES, Og. Constituição, processo e prisão: comentários aos artigos 283 a 310 do CPP, na redação da Lei 12.403/2011. In: (coord.). Medidas cautelares no processo penal: prisões e suas alternativas: comentários à Lei 12.403, de 04.05.2011. São Paulo: Revista dos Tribunais, 2011. 
FERRAJOLI, Luigi. Direito e razão: teoria do garantismo penal. São Paulo: Revista dos Tribunais, 2002.

FRANCO, Alberto Silva; NUCCI, Guilherme de Souza (organizadores). Direito penal, v.7. São Paulo, Revista dos Tribunais, 2010.

. Crimes hediondos. 5a ed. São Paulo: Revista dos Tribunais, 2005.

FREITAS, Jéssica Oníria Ferreira de. Crise da justiça criminal e admissão de espaços de oportunidade no processo penal brasileiro: a proposta do plea bargaining. In: BRODT, Luís Augusto Sanzo; SIQUEIRA, Flávia (orgs.). Limites do poder punitivo: diálogos na ciência penal contemporânea. Belo Horizonte: D'Plácido, 2016. Disponível em: http://201.23.85.222/biblioteca/index.asp?codigo_sophia=131516. Acesso em: 2 jan. 2020.

GAZZOLA, Gustavo dos Reis. Delação premiada. In: CUNHA, Rogério Sanches; TAQUES, Pedro (Coord.); GOMES, Luiz Flávio. Limites constitucionais da investigação. São Paulo: Revista dos Tribunais, 2009.

GIACOMOLLI, Nereu; VASCONCELLOS, Vinicius Gomes de. Justiça Criminal Negocial: Crítica à Fragilização da Jurisdição Penal em um Cenário de Expansão dos Espaços de Consenso no Processo Penal. Revista Novos Estudos Jurídicos. v. 20, n 3. 2015.

GOMES, Luiz Flávio; CERVINI, Raúl. Crime organizado: enfoques criminológico, jurídico (Lei 9.034/95) e político-criminal. 2a ed. São Paulo: Revista dos Tribunais, 1997. . Lei de proteção a vítimas e testemunhas: primeiras considerações. In: PENTEADO, Jaques de Camargo (coord.). Justiça penal, 7: críticas e sugestões: justiça criminal moderna: proteção à vítima e à testemunha, comissões parlamentares de inquéritos, crimes de informática, trabalho infantil, TV e crime. São Paulo: Revista dos Tribunais, 2000 .

25 anos depois, direito penal 3.0. Boletim IBCCRIM, São Paulo, v. 25, n. 298, p. 2-4., $\quad$ set. $2017 . \quad$ Disponível em: http://201.23.85.222/biblioteca/index.asp?codigo_sophia=137780. Acesso em: 4 jan. 2020. 
GOMES, Mariângela Gama de Magalhães. O valor normativo da jurisprudência penal. Tese de Doutorado sob orientação da Professora Ivette Senise Ferreira, Faculdade de Direito da Universidade de São Paulo, 2007.

GOMES FILHO, Antonio Magalhães. Presunção de inocência e prisão cautelar. São Paulo: Saraiva, 1991.

Também em matéria processual provoca inquietação a Lei anti-crime organizado. Boletim IBCCRIM, ed. 13, fev. 1994.

. O crime organizado e as garantias processuais. Boletim IBCCRIM, São Paulo, n. 21, p. $\quad$ 08., set. $1994 . \quad$ Disponível em: http://201.23.85.222/biblioteca/index.asp?codigo_sophia=13592. Acesso em: 5 jan. 2020.

. Notas sobre a terminologia da prova. Reflexos no processo penal brasileiro. In: YARSHELL, Flavio Luiz; MORAES, Mauricio Zanoide. Estudos em homenagem à Profa. Ada Pellegrini Grinover. São Paulo: DPJ, 2005.

Presunção de inocência: princípios e garantias. In: Escritos em homenagem a Alberto Silva Franco, São Paulo: Revista dos Tribunais, 2003.

; TORON, Alberto Zacharias; BADARÓ, Gustavo Henrique (coords). Código de processo penal comentado. 2. ed. São Paulo: Thomson Reuters, 2018. Disponível em: $<$ http://201.23.85.222/biblioteca/index.asp?codigo_sophia=154272>. Acesso em: 5 jan. 2020.

GOULART, José Eduardo. Princípios informadores do direito da execução penal. São Paulo, Revista dos Tribunais, 1994.

GRINOVER, Ada Pellegrini. O crime organizado no sistema italiano. In: PENTEADO, Jaques de Camargo (coord.). Justiça penal, 3: críticas e sugestões. São Paulo: Revista dos Tribunais, 1995. 
. O crime organizado na legislação brasileira. In: CARVALHO, Milton Paulo de (coord.). Temas atuais de direito. São Paulo: LTr, 1998.

GRECO FILHO, Vicente. Comentários à Lei de Organização Criminosa: Lei n. 12.850/13. São Paulo: Saraiva, 2014.

JESUS, Damásio Evangelista de. O fracasso da delação premiada. Boletim IBCCRIM, ed. 21, set. 1994.

. Lei antitóxicos anotada. 8a ed. São Paulo, Saraiva, 2005.

LEMOS, Bruno Espiñeira; QUINTIERE, Víctor Minervino. Técnicas especiais de investigação no processo penal. Belo Horizonte: D'Plácido, 2017.

LEMOS JÚNIOR, Arthur Pinto de; OLIVEIRA, Beatriz Lopes de. Crime organizado e a Lei n. 12.850/13. São Paulo: Verbatim, 2014.

LEWANDOWSKI, Enrique Ricardo. A colaboração premiada em face do princípio da separação dos poderes. In: TOFFOLI, José Antonio Dias (org.). 30 anos da constituição brasileira: democracia, direitos fundamentais e instituições. Rio de Janeiro, Forense, 2018.

LIMA, Camile Eltz de; OSÓRIO, Fernanda Corrêa. Considerações sobre a colaboração premiada: análise crítica do instituto introduzido com o advento da Lei ${ }^{\circ}$ 12.850/2013. In: PRADO, Geraldo; CHOUKR, Ana Cláudia Ferigato; JAPIASSÚ, Carlos Eduardo Adriano. Processo penal e garantias: estudos em homenagem ao professor Fauzi Hassan Choukr. 2a ed. São Paulo: Empório do direito, 2015.

LOPES JR., Aury. Direito processual penal. São Paulo: Saraiva, 2015.

; ROSA, Alexandre Morais da. A pena fixada na delação premiada vincula o julgador na sentença?. Consultor Jurídico, 2017. Disponível em <https://www.conjur.com.br/2017mar-03/limite-penal-pena-fixada-delacao-premiada-vincula-julgador-sentenca> Acesso em: 7 jan. 2020. 
MAIA, Rodolfo Tigre. Dos crimes contra o sistema financeiro nacional: anotações à Lei Federal n. 7.492/86. São Paulo: Malheiros,1999.

MANDARINO, Renan Posella. Limites probatórios da delação premiada frente à verdade no processo penal. In: Ferraz, Esther de Figueiredo. Aspectos penais controversos da colaboração premiada. Monografias vencedoras 2016 - IASPE/CIEE. São Paulo: IASP Instituto dos Advogados de São Paulo, 2016.

MANZADO, Luis Fernando de Moraes; ESSADO, Tiago Cintra. Colaboração premiada: entre a eficiência e o garantismo. In: VAZ, Denise Provasi (Org.). Eficiência e garantismo no processo penal: estudos em homenagem a Antonio Scarance Fernandes. São Paulo: LiberArs, 2017.

MELO, Valber; BROETO, Filipe Maia. O pacote "anticrime" e seus impactos na colaboração premiada. Consultor Jurídico, 29 dez. 2019. Disponível em: $<$ https://www.conjur.com.br/2019-dez-29/pacote-anticrime-impactos-colaboracaopremiada>. Acesso em: 6 jan. 2020.

MENDES, Soraia da Rosa (coord.). A delação/ colaboração premiada em perspectiva. Brasília: IDP, 2016.

MENDONÇA, Andrey Borges de. A colaboração premiada e a nova Lei do Crime Organizado (Lei 12.850/2013). Custos Legis: Revista eletrônica do Ministério Público Federal, v. 4, 2013.

Os benefícios possíveis na colaboração premiada: entre a legalidade e a autonomia da vontade. In: BOTTINI, Pierpaolo Cruz (Coord.); Moura, Maria Thereza de Assis (Coord.). Colaboração Premiada. São Paulo: Revista dos Tribunais, 2017.

MENDRONI, Marcelo Batlouni. Crime de lavagem de dinheiro. São Paulo: Atlas, 2006. Crime organizado: aspectos gerais e mecanismos legais. São Paulo: Atlas, 2016. 
MESQUITA JÚNIOR, Sídio Rosa da. Execução Criminal: teoria e prática: doutrina, jurisprudência, modelos. São Paulo: Atlas, 2005.

MORAES, Maurício Zanoide de. Presunção de inocência no processo penal brasileiro: análise de sua estrutura normativa para a elaboração legislativa e para a decisão judicial. Rio de Janeiro: Lumen Juris, 2010.

; SMANIO, Gianpaolo Poggio. Legislação penal especial. São Paulo: Atlas, 2008.

MOSSIN, Heráclito Antônio. Delação premiada: aspectos jurídicos. 3a ed. Leme: J. H. Mizuno, 2018.

NUCCI, Guilherme de Souza. Individualização da pena. São Paulo: Revista dos Tribunais, 2005.

; MOURA, Maria Thereza Rocha de Assis. Execução penal. São Paulo: Revista dos Tribunais, 2012.

. Provas no processo penal. 3a ed. São Paulo: Revista dos Tribunais, 2013.

. Curso de direito penal, parte geral vol. 1. Rio de Janeiro: Editora Forense, 2016.

. Há limites para o prêmio da colaboração premiada? Consultor Jurídico, 2017. Disponível em: <https:/www.conjur.com.br/2017-jul-03/guilherme-nucci-limites-premiocolaboracao-premiada>. Acesso em: 6 de jan. 2020.

OLIVEIRA, Rafael Serra. Consenso no processo penal: uma alternativa para a crise do sistema criminal. São Paulo: Almedina, 2015.

PEREIRA, Flávia Rahal Bresser. A publicidade no processo penal brasileiro: confronto com o direito à intimidade. Dissertação de mestrado sob orientação de Sérgio Marcos de Moraes Pitombo, São Paulo: Faculdade de Direito da Universidade de São Paulo, 2000. 
PEREIRA, Frederico Valdez. Delação premiada: legitimidade e procedimento; aspectos controvertidos do instituto da colaboração premiada de coautor de delitos como instrumento de enfrentamento do crime organizado. 3. ed. Curitiba: Juruá, 2016.

PRADO, Geraldo; MALAN, Diogo. (Org.). Processo penal e democracia: estudos em homenagem aos 20 anos da Constituição da República de 1988. Rio de Janeiro: Lumen Juris, 2009.

PRADO, Luiz Regis; HAMMERSCHMIDT, Denise; MARANHÃO, Douglas Bonaldi; COIMBRA, Mário. Direito de execução penal. 3a ed. São Paulo: Revista dos Tribunais, 2013.

PITOMBO, Antônio Sérgio Altieri de Moraes. Tipificação da organização criminosa. Tese de doutorado orientada por Ivette Senise Ferreira. Faculdade de Direito da Universidade de São Paulo. São Paulo, 2007.

RIQUERT, Marcelo Alfredo. La delación premiada en el derecho penal: el "arrepentido": una "técnica especial de investigación" en expansión. Buenos Aires: Hammurabi, 2011.

RODRÍGUEZ, Laura Zúñiga. Criminalidad organizada, derecho penal y sociedad. Apuntes para el análisis. In MULAS, Nieves Sanz (coord.). El desafío de la criminalidad organizada. Granada: Comares, 2006.

RODRIGUEZ, Víctor Gabriel. Delação premiada: limites éticos ao Estado. Rio de Janeiro: Forense, 2018.

RODRIGUES, Anabela Maria Pinto Miranda. Novo olhar sobre a questão penitenciária: estatuto jurídico do recluso e socialização, jurisdicionalização, consensualismo e prisão. São Paulo: Revista dos Tribunais, 2001. Disponível em: <http://201.23.85.222/biblioteca/index.asp?codigo_sophia=8777>. Acesso em: 5 jan. 2020.

ROIG, Rodrigo Duque Estrada. Execução penal: teoria crítica. 4a ed. São Paulo: Saraiva Educação, 2018. 
ROMERO, Eneas Romero. A Colaboração premiada. In: BADARÓ, Gustavo Henrique [et alii]; AMBOS, Kai; ROMERO, Eneas (coords). Crime organizado: análise da lei 12.850/2013, São Paulo: Marcial Pons, CEDPAL, 2017.

ROSA, Alexandre Morais da. Como funciona o mercado oculto da delação premiada. Consultor Jurídico, 2016. Disponível em <https://www.conjur.com.br/2016-nov18/limite-penal-funciona-mercado-oculto-delacao-premiada> Acesso em: 6 de out. 2019.

. Para entender a delação premiada pela teoria dos jogos: táticas e estratégias do negócio jurídico. Florianópolis: EModara, 2018.

ROSA, Antonio José Miguel Feu. Execução penal. São Paulo: Revista dos Tribunais, 1995. Disponível em: http://201.23.85.222/biblioteca/index.asp?codigo_sophia=7015. Acesso em: 5 jan. 2020.

SAlVADOR NETTO, Alamiro Velludo. Curso de execução penal. São Paulo: Thomson Reuters Brasil, 2019.

Execução penal: ambiente de cogência ou espaço de dispositividade? Boletim IBCCRIM, edição 324, São Paulo, nov. 2019.

SANCTIS, Fausto Martin de. Crime organizado e lavagem de dinheiro: destinação de bens apreendidos, delação premiada e responsabilidade social. 2a ed. São Paulo: Saraiva, 2015.

SANTOS, Dayana Rosa. O exame criminológico e sua valoração no processo de execução penal. Dissertação de mestrado sob orientação do Professor Antonio Magalhães Gomes Filho, Faculdade de Direito da Universidade de São Paulo, 2013.

SANTOS, Marcos Paulo Dutra. Colaboração (delação premiada). 2a ed. Salvador: JusPODIVM, 2017. 
Colaboração unilateral premiada como consectário lógico das balizas constitucionais do devido processo legal brasileiro. Revista brasileira de direito processual penal. v. 3, n. 1. Belo Horizonte, 2017. p. 131-166. Disponível em: <http://201.23.85.222/biblioteca/index.asp?codigo_sophia=133453>. Acesso em: 5 jan. 2020.

SANTOS, Juarez Cirino dos. Crime organizado. In: PRADO, Luiz Regis. DOTTI; René Ariel (coord.). Direito penal empresarial, crime organizado, extradição e terrorismo: volume VI. São Paulo: Revista dos Tribunais, 2011.

Direito Penal: parte geral. 6a ed. Curitiba, ICPC Cursos e Edições, 2014.

SCHMIDT, Andrei Zenkner. O princípio da legalidade penal no estado democrático de direito. Porto Alegre: Livraria do advogado, 2001.

SILVA, Eduardo Araujo da. Crime Organizado: procedimento probatório. São Paulo: Atlas, 2003.

SILVA, Ézio Vicente da; RIBEIRO, Denisse Dias Rosas. Colaboração premiada e investigação: princípios, vulnerabilidades e validação da prova obtida de fonte humana. Barueri: Novo Século Editora, 2018.

SILVA, José Adaumir Arruda da; SILVA NETO, Arthur Corrêa da. Execução penal: novos rumos, novos paradigmas. Manaus: Aufiero, 2012.

SIQUEIRA FILHO, Élio Wanderley de. Repressão ao crime organizado: inovações da Lei 9.034/95. Curitiba: Juruá, 1995.

SILVEIRA, Renato de Mello Jorge. Organização e associação criminosa nos crimes econômicos: realidade típica ou contradição em termos? In: OLIVEIRA, William Terra; NETO, Pedro Ferreira Leite.; ESSADO, Tiago Cintra; SAAD-DINIZ, Eduardo (org.). Direito penal econômico: estudos em homenagem aos 75 anos do Professor Klaus Tiedermann, São Paulo: LiberArs, 2013. 
A definição de crime organizado. In: (coord.). Crônicas franciscanas do mensalão: comentários pontuais do julgamento da ação penal $n^{\circ} 470$, junto ao STF, pelos professores de direito penal da Universidade de São Paulo (USP). São Paulo: Quartier Latin, 2014.

SOBRINHO, Mário Sérgio. O crime organizado no Brasil. In: FERNANDES, Antonio Scarance; ALMEIDA, José Raul Gavião de; MORAES, Maurício Zanoide de (coord.). Crime organizado: aspectos processuais. São Paulo: Revista dos Tribunais, 2009.

SZNICK, Valdir. Crime organizado: comentário. São Paulo, LEUD, 1997.

STRECK, Lenio. O estranho caso que fez o STF sacrificar a presunção de inocência. Consultor Jurídico, 11 ago. 2016. Disponível em: <http://www.conjur.com.br/2016-ago11/senso-incomum-estranho-fez-stf-sacrificar-presuncao-inocencia>. Acesso em: 7 jan. 2020.

TEMER, Michel Miguel Elias. Benefícios para casos penais. Folha de São Paulo, edição de 12 de novembro de 1994. Primeiro Caderno, p. 3. Disponível em: $<$ https://acervo.folha.com.br/leitor.do?numero=12605\&anchor=4841797\&origem=busca\& pd=51c0fe27f2ea4555dafcff1c7ecb46f9>. Acesso em: 5 de jan. 2020.

TORON, Alberto Zacharias, Crimes hediondos: o mito da repressão penal: um estudo sobre o recente percurso da legislação brasileira e as teorias da pena. São Paulo: Revista dos Tribunais, 1996.

TUCCI, Rogério Lauria. Direitos e garantias individuais no processo penal brasileiro. $2 \mathrm{a}$ ed. São Paulo: Revista dos Tribunais, 2004.

. Tráfico de drogas. In: FRANCO, Alberto Silva; NUCCI, Guilherme de Souza (organizadores). Direito penal, v.7. São Paulo: Revista dos Tribunais, 2010. 
VASCONCELLOS, Vinicius Gomes de. Colaboração premiada e não oferecimento da denúncia: o espaço de oportunidade do art. $4 .^{\circ}$, § 4..$^{\circ}$, da Lei 12.850/2013. Boletim IBCCRIM, São Paulo, v. 23, n. 268, p. 13-15, mar. 2015.

. Barganha e justiça criminal negocial: análise das tendências de expansão dos espaços de consenso no processo penal brasileiro, São Paulo: IBCCRIM, 2015.

; SOUSA, Matheus Herren Falivene de. Código de ética da advocacia na justiça criminal negocial: proposta de regras deontológicas para integridade defensiva na colaboração premiada. Boletim IBCCRIM, São Paulo, v. 26, n. 303, p. 13-15, fev. 2018.

. Não-obrigatoriedade e acordo penal na resolução 181/2017 do Conselho Nacional do Ministério Público. Boletim IBCCRIM, São Paulo, v. 25, n. 299, p. 7-9, out. 2017.

Colaboração premiada no processo penal. $2 \mathrm{a}$ ed. São Paulo: Thomson Reuters Brasil, 2018.

WEDY, Miguel Tedesco; KLEIN, Maria Eduarda Vier. O futuro do direito penal negocial e o Estado Democrático de Direito. Revista Brasileira de Ciências Criminais, São Paulo, v. 27, n. 156, p. 279-306, jun. 2019. Disponível em: <http://201.23.85.222/biblioteca/index.asp?codigo_sophia=151450>. Acesso em: 5 jan. 2020.

ZAFFARONI, Eugenio Raúl. "Crime organizado": uma categorização frustrada. Discursos sediciosos: crime, direito e sociedade. Ano 1, $\mathrm{n}^{\circ} 1,1^{\circ}$ sem., 1996. Relime Dumará. Disponível em <https://www.passeidireto.com/arquivo/61907478/zaffaroni-raul-crimeorganizado-uma-categoria-frustrada>. Acesso em: 16 out. 2019.

ZILLI, Marcos Alexandre. A colaboração premiada nos trópicos. Autonomia das partes e o imperativo do controle judicial. Leituras sobre a Lei 12.850/13 à luz da eficiência e do garantismo. In: CUNHA FILHO, Alexandre Jorge Carneiro da (coord.); ARAÚJO, Glaucio Roberto Brittes de (coord.); LIVIANU, Roberto (coord.); PASCOLATI JUNIOR, Ulisses Augusto (coord.). 48 visões sobre a corrupção. São Paulo: Quartier Latin, 2016. 
. Pelo movimento antropófago do processo penal: to bargain or not to bargain? eis questão. In. MALAN, Diogo; BADARÓ, Gustavo Henrique; ZILLI, Marcos; MOURA, Maria Thereza Rocha de Assis; SAAD, Marta; MORAES; Mauricio Zanoide de. [orgs.]. Processo penal humanista: escritos em homenagem a Antonio Magalhães Gomes Filho. Belo Horizonte: Editora D’Plácido, 2019. 